Revista Destaques Acadêmicos, Lajeado, v. 12, n. 3, 2020. ISSN 2176-3070

DOI: http://dx.doi.org/10.22410/issn.2176-3070.v12i3a2020.2713

http://www.univates.br/revistas

\title{
O HOMEM NO CONTEXTO GRAVÍDICO-PUERPERAL: UMA REVISÃO INTEGRATIVA
}

\author{
Eliane dos Passos ${ }^{1}$, Cecília Drebes Pedron ${ }^{2}$
}

Resumo: Este estudo objetiva identificar as evidências do envolvimento dos homens no ciclo gravídico-puerperal. Trata-se de uma revisão integrativa que teve como questão norteadora: Qual o envolvimento dos homens no ciclo gravídico-puerperal? Os artigos foram coletados na Biblioteca Virtual em Saúde com os descritores e operadores boleanos "percepção" and "pai" and "parto"; "pai" and "parto"; e "pai" and "gravidez". Após a aplicação dos critérios de inclusão e exclusão a busca resultou na seleção de 12 estudos. Os achados foram analisados em categorias temáticas, tendo aproximações com a Análise de Conteúdo. As categorias temáticas que emergiram delineiam a participação do homem no ciclo gravídico-puerperal demonstrando as interconexões entre suas diferentes fases. Os resultados também inseriram o homem no acompanhamento do parto e as conexões com a gestante, bem como a interação no pós-parto, aproximando com o recém-nascido. Sendo assim, o estudo demonstrou que o homem possui espaço de participação no ciclo gravídico-puerperal, pois o mesmo oferece o apoio necessário ao grupo familiar.

Palavras-chave: Papel do Homem; Gravidez; Parto; Pai, Percepção.

\section{INTRODUÇÃO}

O ciclo gravídico-puerperal é contemplado por políticas públicas que favorecem a assistência especializada e contínua do grupo familiar, tendo visto que nesta fase, a família é inserida no plano de cuidados, tendo como objetivo a integralidade e vinculação com a equipe de saúde (GULLO et al., 2020). A equipe de saúde por si é composta por vários profissionais que atuam frente à assistência neste período, fazendo o acompanhamento de um modo

1 Enfermeira. Discente do curso de Especialização em Enfermagem Obstétrica pela Universidade do Vale do Taquari - Univates. E-mail: elianedospassos@hotmail.com

2 Professora Doutora em Enfermagem atuante no Departamento de Enfermagem MaternoInfantil. Coordenadora do Laboratório de Ensino Virtual em Enfermagem UFRGS - LEVi. Escola de Enfermagem da Universidade Federal do Rio Grande do Sul. E-mail: cepedron@ gmail.com 
interdisciplinar, ou seja, estruturando um plano de ensino fundamentado nas trocas de conhecimento de cada especialidade de compõe o serviço de saúde (SOUSA, 2020).

A inserção da família no processo assistencial de gestação e puerpério vêm ao encontro da evolução na maneira em que a mulher é tratada durante o período, dado o preconceito histórico principalmente nos aspectos estéticos do corpo feminino e esquecimento do pilar emocional que fundamenta o bemestar (SOUZA et al., 2020). O cuidado com a mulher sempre esteve em segundo plano, sendo a preferência e necessidade direcionada para a preservação da vida do recém-nascido, independente dos contratempos e intercorrências que ocorriam em sua maioria durante o parto (CABRAL; PEREZ, 2020).

$\mathrm{O}$ cuidado enfocado no recém-nascido e criança perdurou durante alguns séculos, sendo resguardados pelos primeiros programas de saúde com o intuito de reduzir a mortalidade infantil e implementar ações oriundas da evolução da medicina do século XIX (LOPES et al., 2020). Os avanços da medicina foram sendo estruturados, surgiram as profissões modernas ligadas à área da saúde, e as primeiras políticas públicas começaram a ser implantadas e por volta de 1960 (AMORIM et al., 2020).

Sendo assim, a assistência integral para a mulher começou a ser incorporada ao processo saúde-doença no Brasil somente em meados dos anos 1990, quando políticas públicas como a Lei 8080/90, que estruturou a base para o Sistema Único de Saúde (SUS), foram implementadas. (SERRÃO et al., 2020). As práticas de cuidado integral foram implementadas por meio de políticas públicas e fomento à realização de estratégias de promoção à saúde e reabilitação quando necessário (SANTOS, 2020).

Contudo, a atenção ao ciclo gravídico-puerperal permaneceu reprimida por algumas décadas, dando espaço para gestações com intercorrências pela falta de acompanhamento de pré-natal, a ocorrência da violência obstétrica e o aumento expressivo nas taxas de cesarianas, sendo o estigma pelo processo de parto natural uma das causas (AMORIM et al., 2020). Atualmente ocorre um movimento inverso, com a disponibilização de programas de atenção integral e resolutiva ao cuidado voltado para o grupo familiar, atentando para as especificações de seu contexto social e cultural, respeitando as individualidades e instituindo o trabalho interdisciplinar das equipes de saúde (LOPES et al., 2020).

A integralidade deste processo suscita na necessidade do homem apoiar a mulher durante o ciclo gravídico-puerperal, estando como uma figura essencial para a segurança e desafios que a gestante enfrenta com as mudanças e situações geradas pela gravidez (MENDES et al., 2020). Além de apoiar a mulher, o homem pode dividir as responsabilidades, sendo que as mesmas aumentam principalmente com a chegada do recém-nascido, inferindo também sobre o acompanhamento e vinculação com o filho, construindo uma relação natural e saudável (SANTANA e SILVA GONÇALVES, 2020). 
Dessa forma, Matos et al. (2017) comentam sobre a importância da presença do pai para a vinculação com o recém-nascido e aproximação entre os entes familiares. Para Nascimento et al. (2020) o pai no contexto de referência do recém-nascido, auxilia a mulher nos cuidados gerais de rotina, bem como apoia na tomada de decisão sobre os procedimentos necessários para esse período, constituindo assim uma figura importante e necessária para a família.

Assim, este estudo justifica-se pela necessidade de compreender o papel que o homem vem desempenhando no processo gravídico-puerperal, instrumentalizando os benefícios de sua presença e auxílio, principalmente para a qualidade de vida do grupo familiar. Desta forma, a questão norteadora foi: Qual o envolvimento dos homens no ciclo gravídico-puerperal? E, buscando responder ao questionamento, objetivou-se neste trabalho identificar as evidencias de envolvimento dos homens no ciclo gravídico-puerperal.

\section{METODOLOGIA}

Este estudo é caracterizado como uma revisão integrativa, seguindo os pressupostos dos autores Mendes, Silveira e Galvão (2008). Em suma, os autores citados estruturam a revisão integrativa em seis etapas que são descritas a seguir: delimita-se o tema, integrando a hipótese e a questão central da pesquisa, seguida pela segunda etapa em que se delimitam os critérios de inclusão e exclusão, na terceira é estruturado o quadro com algumas informações dos achados, na quarta os achados são avaliados, depois de interpretados no quinto passo, e apresentados ao leitor em sua última etapa (MENDES; SILVEIRA e GALVÃO, 2008).

Seguindo a questão norteadora, iniciou-se o processo de pesquisa, definindo-se como base de busca o Portal Regional da Biblioteca Virtual em Saúde (BVS). Os descritores definidos estão de acordo com os Descritores em Ciências da Saúde (DeCS) sendo descritos a seguir junto com os operadores boleanos, "percepção" and "pai" and "parto"; "pai" and "parto"; "pai" and "gravidez". A busca foi realizada em dezembro de 2019.

Os critérios de inclusão delimitados foram: artigos científicos originais que abordassem a temática pesquisada; disponibilidade integral do artigo em formato gratuito e on-line; Idioma português e que tenha sido publicado nos últimos cinco anos, sendo o período compreendido entre novembro de 2014 a novembro de 2019. Delimitaram-se como critérios de exclusão aqueles identificados em formato de monografia, dissertação, tese, livro ou quaisquer outros formatos que descaracterizem um artigo científico. Foram observados os artigos achados em duplicidade na busca realizada, sendo considerada apenas uma versão, a primeira na ordem de aparecimento no filtro de busca.

Neste sentido, os achados foram analisados, sendo aplicado os critérios de inclusão e exclusão e, depois realizado o preenchimento do quadro contendo os dados dos autores, título do artigo, periódico e ano de publicação 
e o delineamento da pesquisa. Cada artigo foi identificado pela letra A seguido de sequência numérica sendo identificados desta forma durante as discussões. Ainda durante a leitura dos artigos, os mesmos tiveram seus conteúdos analisados e categorizados por pontos temáticos compatíveis com aproximações com a Análise de Conteúdo (BARDIN, 2016). Aos achados da pesquisa foram respeitados os critérios éticos, realizando a sua correta interpretação e citação, sendo referenciados na respectiva seção deste estudo.

\section{RESULTADOS}

Na presente seção foram apresentados os dados da busca realizada, as informações encontram-se compiladas no Quadro 1. O referido quadro integra todos os 12 estudos analisados, destacando informações pertinentes como: Autor(es); Título do artigo; Periódico; Ano de publicação e Delineamento da pesquisa.

Quadro 1. Apresentação dos artigos encontrados.

\begin{tabular}{|c|c|c|c|c|c|}
\hline $\mathbf{N}^{\circ}$ & Autor(es) & Título do artigo & Periódico & Ano & $\begin{array}{l}\text { Delineamento da } \\
\text { pesquisa }\end{array}$ \\
\hline A1 & $\begin{array}{l}\text { NASCIMENTO, } \\
\text { Adriana Oliveira } \\
\text { et al. }\end{array}$ & $\begin{array}{l}\text { A importância do } \\
\text { acompanhamento } \\
\text { paterno no pós-parto e o } \\
\text { exercício da paternidade }\end{array}$ & $\begin{array}{l}\text { Rev. pesqui. } \\
\text { cuid. } \\
\text { fundam. } \\
\text { (Online) } \\
\end{array}$ & 2019 & $\begin{array}{l}\text { Pesquisa } \\
\text { qualitativa }\end{array}$ \\
\hline A2 & $\begin{array}{l}\text { BRAIDE, Andrea } \\
\text { Stopiglia Guedes } \\
\text { et al. }\end{array}$ & $\begin{array}{l}\text { Sou homem e pai sim! } \\
\text { (Re) construindo a } \\
\text { identidade masculina a } \\
\text { partir da participação no } \\
\text { parto }\end{array}$ & $\begin{array}{l}\text { Rev Panam } \\
\text { Salud } \\
\text { Publica }\end{array}$ & 2018 & $\begin{array}{l}\text { Pesquisa } \\
\text { qualitativa }\end{array}$ \\
\hline A3 & $\begin{array}{l}\text { QUITETE, } \\
\text { Jane Baptista; } \\
\text { MONTEIRO, Jéssika } \\
\text { Andrade de Melo } \\
\text { Braga } \\
\end{array}$ & $\begin{array}{l}\text { A participação do pai } \\
\text { no parto domiciliar } \\
\text { planejado: um ato } \\
\text { significativo para a } \\
\text { mulher }\end{array}$ & $\begin{array}{l}\text { Rev. enferm. } \\
\text { UERJ }\end{array}$ & 2018 & $\begin{array}{l}\text { Pesquisa } \\
\text { qualitativa }\end{array}$ \\
\hline $\mathrm{A} 4$ & $\begin{array}{l}\text { RIBEIRO, José } \\
\text { Francisco et al. }\end{array}$ & $\begin{array}{l}\text { Percepção do pai sobre a } \\
\text { sua presença durante o } \\
\text { processo parturitivo }\end{array}$ & \begin{tabular}{|l|} 
Rev. enferm. \\
UFPE on \\
line \\
\end{tabular} & 2018 & $\begin{array}{l}\text { Pesquisa } \\
\text { qualitativa }\end{array}$ \\
\hline A5 & $\begin{array}{l}\text { HOLANDA, Sâmia } \\
\text { Monteiro et al. }\end{array}$ & $\begin{array}{l}\text { Influência da } \\
\text { participação do } \\
\text { companheiro no pré- } \\
\text { natal: satisfação de } \\
\text { primíparas quanto ao } \\
\text { apoio no parto }\end{array}$ & $\begin{array}{l}\text { Texto \& } \\
\text { contexto } \\
\text { enferm }\end{array}$ & 2018 & $\begin{array}{l}\text { Pesquisa } \\
\text { quantitativa }\end{array}$ \\
\hline A6 & $\begin{array}{l}\text { CARVALHO, Isaiane } \\
\text { da Silva et al. }\end{array}$ & $\begin{array}{l}\text { A participação do } \\
\text { homem durante o } \\
\text { nascimento do filho: } \\
\text { vídeos do Youtube }\end{array}$ & $\begin{array}{l}\text { Rev. enferm. } \\
\text { UERJ }\end{array}$ & 2017 & $\begin{array}{l}\text { Pesquisa } \\
\text { quantitativa }\end{array}$ \\
\hline A7 & $\begin{array}{l}\text { MATOS, Mariana } \\
\text { Gouvêa et al. }\end{array}$ & $\begin{array}{l}\text { Construindo o Vínculo } \\
\text { Pai-Bebê: A Experiência } \\
\text { dos Pais }\end{array}$ & Psico USF & 2017 & $\begin{array}{l}\text { Pesquisa } \\
\text { qualitativa }\end{array}$ \\
\hline
\end{tabular}




\begin{tabular}{|c|c|c|c|c|c|}
\hline $\mathrm{N}^{\mathrm{o}}$ & Autor(es) & Título do artigo & Periódico & Ano & $\begin{array}{l}\text { Delineamento da } \\
\text { pesquisa }\end{array}$ \\
\hline A8 & $\begin{array}{l}\text { SANTOS, Rosângela } \\
\text { da Silva; CAIRES, } \\
\text { Tharine Louise } \\
\text { Goncalves }\end{array}$ & $\begin{array}{l}\text { Sentimentos, sensações } \\
\text { e emoções dos pais } \\
\text { que vivenciaram o } \\
\text { nascimento de seus } \\
\text { filhos }\end{array}$ & $\begin{array}{l}\text { Cienc. } \\
\text { enferm }\end{array}$ & 2016 & $\begin{array}{l}\text { Pesquisa } \\
\text { qualitativa }\end{array}$ \\
\hline A9 & $\begin{array}{l}\text { SILVA, Elza } \\
\text { Monteiro et al. }\end{array}$ & \begin{tabular}{|l|} 
Participação do \\
companheiro nos \\
cuidados do binômio \\
mãe e filho: percepção \\
de puérperas \\
\end{tabular} & $\begin{array}{l}\text { Rev. pesqui. } \\
\text { cuid. } \\
\text { fundam. } \\
\text { (Online) }\end{array}$ & 2016 & $\begin{array}{l}\text { Pesquisa } \\
\text { qualitativa }\end{array}$ \\
\hline A10 & $\begin{array}{l}\text { FRANCISCO, Bruna } \\
\text { de Souza et al. }\end{array}$ & \begin{tabular}{|l|} 
Percepções dos pais \\
sobre suas vivências \\
como acompanhantes \\
durante o parto e \\
nascimento \\
\end{tabular} & $\begin{array}{l}\text { REME rev. } \\
\text { min. enferm }\end{array}$ & 2015 & $\begin{array}{l}\text { Pesquisa } \\
\text { qualitativa }\end{array}$ \\
\hline A11 & $\begin{array}{l}\text { MELO, Raimunda } \\
\text { Maria et al. }\end{array}$ & $\begin{array}{l}\text { Conhecimento de } \\
\text { homens sobre o trabalho } \\
\text { de parto e nascimento }\end{array}$ & $\begin{array}{l}\text { Esc. Anna } \\
\text { Nery Rev. } \\
\text { Enferm }\end{array}$ & 2015 & $\begin{array}{l}\text { Pesquisa } \\
\text { qualitativa }\end{array}$ \\
\hline A12 & $\begin{array}{l}\text { ANTUNES, Juliana } \\
\text { Teixeira et al. }\end{array}$ & $\begin{array}{l}\text { Presença paterna na sala } \\
\text { de parto: expectativas, } \\
\text { sentimentos e } \\
\text { significados durante o } \\
\text { nascimento }\end{array}$ & $\begin{array}{l}\text { Rev. enferm. } \\
\text { UFSM }\end{array}$ & 2014 & $\begin{array}{l}\text { Pesquisa } \\
\text { qualitativa }\end{array}$ \\
\hline
\end{tabular}

Fonte: Autora, 2020.

Durante a coleta de dados no Portal Regional da Biblioteca Virtual em Saúde (BVS) foram identificados 5580 artigos que após a aplicação dos critérios de inclusão e exclusão resultaram em 86 artigos os quais foram lidos título e resumo resultando em 31 artigos. Após a leitura minuciosa dos artigos 12 deles responderam à questão norteadora sendo o material discutido neste artigo.

Dentre os achados, destacam-se um artigo publicado no ano de 2019, quatro em 2018, dois em 2017, dois em 2016, dois em 2015 e um em 2014. Observando os periódicos de publicação, oito dos 12 artigos foram publicados em revistas da área predominante da enfermagem. No delineamento da pesquisa, identificou-se uma predominância de estudos de natureza qualitativa totalizando 10 artigos e dois com abordagem quantitativa.

\section{DISCUSSÕES}

Nesta seção serão discutidos os resultados desta pesquisa, sendo que a apresentação se deu por meio de três categorias temáticas. A primeira categoria é denominada como "O homem e o ciclo gravídico-puerperal: interconexões entre suas diferentes fases" contextualizando o papel do homem nas diferentes fases do ciclo gravídico-puerperal, intuindo sobre os fatores benéficos de sua participação. Logo após, apresenta-se a segunda categoria intitulada como "O homem no acompanhamento do parto: conexões com a gestante" discutindo a presença do homem no pré-natal e parto, bem como os benefícios aliados a essa prática e os sentimentos vivenciados pelos mesmos. A terceira categoria 
é denominada como "O homem no pós-parto: criando conexões com o recém-nascido" trazendo para discussão a figura do homem no momento de vinculação com o recém-nascido.

\section{O homem e o ciclo gravídico-puerperal: interconexões entre suas diferentes fases}

Nesta categoria estão apresentados os aspectos relacionados à participação do homem no ciclo gravídico-puerperal, com vistas para a aproximação entre a figura de companheiro e paterna para a mulher e o recémnascido. A estrutura que compõe o ciclo gravídico-puerperal é denotada por diversas fases, nas quais a mulher perpassa e necessita de apoio nas diversas frentes, desde o âmbito domiciliar, ambiente de trabalho e nas situações pessoais.

O homem, na figura paterna, apresenta importante papel no apoio emocional à mulher. Além do apoio emocional, a referência do pai nesse processo, confere um reforço para a realização do aleitamento materno, melhor evolução para o parto vaginal e um destaque para o pós-parto, durante a recuperação da gestante (CAVALCANTI; HOLANDA, 2019). O apoio paterno merece destaque nos diferentes âmbitos de cuidado na gestação, deste modo o homem auxilia e oferece segurança para o bem-estar emocional, acompanhamento e presença marcante do grupo familiar (MENDES et al., 2020).

Seguindo o mesmo limiar, uma abordagem destacada retrata a ressignificação da masculinidade durante o processo de gestação, tendo como foco a participação efetiva do homem nos momentos de cuidado e frente ao apoio integral a mulher (A2). Outro ponto refere-se ao fortalecimento da relação familiar com a presença masculina, intuindo e marcando a estrutura física e emocional do momento (A2). A busca por interpretar a masculinidade no acompanhamento da gestação é necessária, auxiliando a mulher e quebrando os preconceitos dos modelos tradicionais de distanciamento do homem (CABRAL; PEREZ, 2020).

A segurança e confiança são os conceitos de ênfase destacados, trabalhando o contexto de participação do homem do trabalho de parto, mas também a importância deste no processo de pré-natal e pós-parto (A4). As discussões do artigo entram nas diferentes abordagens do homem como auxiliar nesses momentos, compondo a estrutura necessária para a sensibilização do público masculino no apoio ao ciclo gravídico-puerperal. A segurança oferecida pelo homem na gestação não é relacionada somente a sua figura masculina e sim pela presença e apoio do grupo familiar nesse momento considerado importante para os integrantes (SANTOS, 2020).

Complementando as discussões, uma pesquisa (A5) foi estruturada a partir das percepções de primíparas sobre a participação do homem no pré- 
natal e incorporando a necessidade de capacitações para esse momento. O limiar estudado é de que o contexto de primíparas é essencialmente de aprendizagem sobre o processo gravídico-puerperal, estimulando também a incorporação do parceiro nessas situações e instrumentalizando as suas funções nesse espaço de tempo e de relações. O ciclo que compreende a gestação é complexo e necessita de capacitações e acompanhamento, sendo assim o homem representa um apoio, em suma das decisões e ações que são realizadas nesse período (SOUSA, 2020).

Ainda assim, outra pesquisa (A8) busca oferecer significados para a participação do pai no acompanhamento da gestação, intuindo sobre as necessidades da mulher e do recém-nascido, interpretando que a função precisa ser clara para o homem. $\mathrm{O}$ estudo descreve inúmeros sentimentos positivos da participação do pai, demonstrando que o homem ao estar presente com a mulher, percebe o processo como seu também, sendo parte integrante e necessária. A presença do homem durante a gestação oferece um grande escopo de significados sobre o seu papel no dia a dia e na estrutura familiar contemplada com o fortalecimento da figura paterna e segura para a gestante (LOPES et al., 2020).

O acompanhamento da gestante também foi foco de estudo (A10) articulando o papel do homem no processo de gestação, fortalecendo o vínculo com a mulher e com o recém-nascido. A estrutura de acompanhamento da gestação foi embasada na inserção e capacitação do homem para o apoio nesse momento, conferindo conhecimento e a quebra de paradigmas necessários para a sua compreensão. A quebra de paradigmas é necessária e assume importância durante a gestação, que oferece a vinculação necessária para a mulher desde as primeiras fases do ciclo gravídico-puerperal (AMORIM et al., 2020).

Sendo assim, a presença do homem no ciclo gravídico-puerperal é irrefutável, os artigos discutidos nessa categoria (A2, A4, A5, A8 e A10), desmistificam os preconceitos e situações que afastam o homem nesse período. As principais questões discutidas foram as que compõem o papel de oferecer segurança para a mulher, nesse quesito o sentimento não é compreendido pelos autores por meio do viés da masculinidade e sim da presença familiar e fortalecimento dos integrantes desse grupo.

\section{O homem no acompanhamento do parto: conexões com a gestante}

Esta categoria retrata a presença do homem no momento do parto, intuindo sobre a sua presença no instante do nascimento e também no acompanhamento do pré-natal e pós-parto. A participação do homem no espaço de parto também é vinculada as conexões com a gestante, estruturando uma profunda afinidade entre os atores para que o processo seja tranquilo e dentro do esperado. 
Iniciamos a apresentação buscando estruturar a essência da masculinidade, compondo o cenário de inserção do homem na gestação, inferindo sobre a sua atuação efetiva e intuitiva como agente integrante do grupo familiar (A2). Compreende-se que a atuação do homem dentro do grupo familiar é intensificada durante a gestação, por ser um período caracterizado pelas transformações tanto físicas, quanto comportamentais da mulher (CABRAL; PEREZ, 2020).

A participação do pai no parto foi discutido assim como sua presença por meio da realização de uma pesquisa de campo (A3), a qual delimitou a percepção da mulher de que o homem é fundamental nesse momento específico. A integração do homem no parto também intui sobre a frequente evolução ao parto normal, sendo considerável o ideal e que confere um maior número de benefícios ao grupo familiar. O parto é um momento especial para o casal, tendo como foco o apoio de ambos sobre os benefícios de um parto tranquilo, prevenindo intercorrências por meio da atenção e do olhar diferenciado sobre essa fase (SERRÃO et al., 2020).

Sob o mesmo limiar uma pesquisa (A4) também versou sobre a figura masculina durante o trabalho de parto, favorecendo a realização do processo natural de nascimento e fortalecendo a vinculação com o a mulher. A vinculação entre o homem e a mulher durante a evolução do parto, e até mesmo na preparação, inferem sobre os benefícios acarretados pela segurança e confiança entre ambos. Assim, a aproximação entre o casal reafirma o potencial da segurança oferecida para o nascimento do bebê e sua vinculação desde o ventre por meio do companheirismo e auxílio (SANTOS, 2020).

A participação do homem no trabalho de parto foi discutida por meio do viés da preparação para essa atividade (A5). A capacitação é tratada como um limiar necessário para construir o conhecimento sobre o processo, estimulando a quebra de paradigmas e preconceitos atrelados a esse momento que por tradição afasta o homem. A preparação do grupo familiar para o parto é parte fundamental no ciclo gravídico-puerperal, conferindo a segurança necessária para o cumprimento dos papeis nesse espaço (SOUZA et al., 2020).

Complementando o estudo anterior, outra pesquisa (A6) estimula a análise sobre a participação do homem no parto por meio do viés da humanização. A humanização do parto faz parte de uma estratégia que visa à qualidade de vida do grupo familiar e o fortalecimento da prática do parto normal ou natural. O estudo (A6) infere que a participação do homem no parto favorece a humanização necessária para que o recém-nascido seja recebido com qualidade e amorosidade. A humanização do parto é um dos preceitos das estruturas de políticas públicas atuais para o bem-estar da família, defendendo a participação do homem durante todo o processo, sob a justificativa de promoção à vinculação com a mulher e o recém-nascido (MENDES et al., 2020).

Os sentimentos dos pais durante o parto também versou discussões (A10). Nesse estudo (A10), os pais relataram que estar com o recém-nascido e a 
esposa durante esse momento é singular, favorecendo a vinculação com ambos. Contudo, denotaram a impotência durante o trabalho de parto, indicando a necessidade de mais capacitações sobre o processo, principalmente por meio da equipe de saúde. A necessidade de acompanhamento pela equipe de saúde é inerente às práticas de promoção a um parto humanizado e seguro, conferindo uma participação efetiva do homem no processo.

Sob o mesmo limiar de conhecimento e capacitação sobre o parto, um artigo (A11) estruturou o pensamento do homem sobre a sua importância nesse momento. Os resultados apresentados indicaram o conhecimento do homem sobe os principais sinais de trabalho de parto, inferindo que o choro do recém-nascido é um fator de alívio e finalização da ansiedade. A pesquisa instrumentaliza a importância do homem no momento de nascimento do filho, favorecendo a vinculação e apoio. O conhecimento que o homem demonstra durante o trabalho de parto, favorece a vinculação com a mulher e a equipe de saúde, além de quebrar os paradigmas sobre o tema (SANTANA; SILVA; GONÇALVES, 2020).

E, por fim foi discutido sobre a participação do pai no trabalho de parto sob o olhar de uma nova experimentação da figura masculina, sendo que o homem oferece apoio e segurança para a mulher, aguardando o recémnascido (A12). Contudo, o homem ainda está descobrindo seu lugar nesse espaço do parto, mesmo que identificada a sua importância, por vezes a falta de conhecimento ou instruções, acaba por tornar o processo traumático. As políticas públicas de humanização defendem a participação do homem no acompanhamento da gestante, oferecendo as capacitações necessárias para um desempenho efetivo e integral da figura paterna (LOPES et al., 2020).

Os artigos elencados nessa categoria (A2, A3, A4, A5, A6, A10, A11 e A12) demonstraram a importância do homem no parto, integrando os aspectos da segurança sobre o grupo familiar e a humanização do nascimento do recém-nascido e favorecimento do parto normal ou natural. Outros aspectos importantes também merecem destaque, como a necessidade de incorporação da capacitação necessária ao homem que deseja participar desse processo nas práticas das equipes de saúde.

\section{O homem no pós-parto: criando conexões com o recém-nascido}

Essa categoria temática estrutura as análises sobre a figura do homem no momento de pós-parto, intuindo sobre a vinculação e espera do recém-nascido no grupo familiar. A inserção do homem como agente integrante e efetivo no pós-parto determina o auxílio e apoio para a parturiente, desempenhando papel essencial nesse contexto.

As discussões sobre a participação do homem no pós-parto permeiam os aspectos de integração dos estudos sobre o auxílio do pai na recuperação da mulher neste momento em específico (CAVALCANTI; HOLANDA, 2019). 
Além dos aspectos relacionados à recuperação da mulher, também se incita sobre a aproximação do homem com o recém-nascido, espelhando os benefícios impares para o grupo familiar. A presença do homem no nascimento do bebê é de suma importância para a vinculação entre a família, compondo assim uma estratégia de humanização e ampliação da qualidade de vida (MENDES et al., 2020).

Na mesma linha de compreensão, uma pesquisa (A2) descreve a pluralidade na presença do homem no momento de cuidado ao recém-nascido. Esses momentos significam o apoio masculino para o pós-parto e desmistificam os preconceitos instaurados culturalmente. A compreensão do papel do pai na gestação e pós-parto é historicamente relacionada aos modelos tradicionais de afastamento físico e psicológico, sendo que a vinculação se perde por meio da lacuna construída nesse momento (SANTANA; SILVA; GONÇALVES, 2020).

A vinculação com o recém-nascido foi discutida em uma pesquisa (A7) que conduz para participação do homem na gestação e em todas as fases que compreendem o ciclo gravídico-puerperal. Contudo, também descreve a importância do homem no acompanhamento do filho, construindo o vínculo por meio da presença e interação cotidiana. A presença do homem no cuidado do recém-nascido é importante, haja vista a significância da interação familiar e fortalecimento da estrutura das funções que cada indivíduo exerce no grupo (SOUZA et al., 2020).

Ainda sobre os aspectos referentes à vinculação entre o homem e o recémnascido, oram destacados principalmente os fatores que favorecem as relações entre os integrantes do grupo familiar na gestação e no pós-parto, o que incita ao cuidado e acompanhamento intenso (A9 e A11). O sentimento de cuidado cerca o casal ao receber o recém-nascido, sendo instintivo o acompanhamento e contato direto com o bebê, manuseando e aplicando o conhecimento adquirido para o bem-estar no pós-parto (AMORIM et al., 2020).

Sendo assim, os artigos analisados (A2, A7, A9 e A11) demonstram que a presença do homem no pós-parto é consistente e necessária para o encaminhamento do parto normal ou natural, bem como a ocorrência de preceitos da humanização. A vinculação entre o homem e o recém-nascido também merece destaque, vislumbrando que a presença do pai no cuidado direto ao bebê fortalece e destaca a sua figura como participante do grupo familiar, também oferecendo segurança e apoio para a mulher.

\section{CONCLUSÕES}

Esta revisão integrativa cumpriu com o objetivo principal de identificar as evidências do envolvimento dos homens no ciclo gravídico-puerperal. A metodologia do estudo possibilitou analisar diferentes cenários de inserção do homem, angariando a ampliação da compreensão sobre a problemática na prática cotidiana nos diferentes níveis de complexidade a saúde. 
Identificou-se que o homem pode realizar todo o acompanhamento da mulher durante o ciclo gravídico-puerperal, favorecendo o apoio e a segurança necessários para esse momento. $\mathrm{O}$ fortalecimento da relação entre o homem e a mulher também reforçam a presença do homem nesse processo, compondo assim uma participação efetiva e integral da figura no grupo familiar.

Outro ponto que merece destaque é a presença do homem durante o parto, suscitando principalmente a necessidade de oferecer capacitações com a finalidade de construir conhecimento e informar sobre as fases do ciclo gravídico-puerperal, favorecendo o auxílio. Além do auxílio, a presença do homem favorece a evolução de um parto normal ou natural, diminuição de intercorrências e promoção da humanização com no trato da parturiente e com o recém-nascido.

E, por fim, a vinculação com o recém-nascido também foi elencada como um dos benefícios da presença do homem no acompanhamento da gestação e no pós-parto. Os cuidados oferecidos pelo homem ao bebê estimulam a significação de um papel masculino intuitivo e pertinente ao grupo familiar.

Assim, este estudo possibilitou a ampliação sobre o conhecimento da participação do homem no ciclo gravídico-puerperal, ponderando sobre a sua importância nos diferentes aspectos que cercam a mulher e o recém-nascido. Ainda, este estudo instiga a realização de outras pesquisas que busquem aprofundar o conhecimento sobre o papel do homem nesse espaço, enriquecendo a disponibilidade de material científico e auxiliando na desconstrução de paradigmas.

\section{REFERÊNCIAS}

AMORIM, Thaís Vasconselos, et al. Mulheres com cardiopatia no contexto do planejamento reprodutivo: contribuições da hermenêutica fenomenológica. Escola Anna Nery, v. 24, n 1, 2020.

ANTUNES, Juliana Teixeira, et al. Presença paterna na sala de parto: expectativas, sentimentos e significados durante o nascimento. Revista de Enfermagem da UFSM, v. 4, n. 3, p. 536-545, 2014. Acesso em: 17 jan. 2020. Disponível em: https:/ / periodicos. ufsm.br/index.php/reufsm/article/view/12515

BARDIN, Laurence. Análise de Conteúdo. Tradução: Luís Augusto Pinheiro. São Paulo: Edições 70, 2016.

BRAIDE, Andrea Stopiglia Guedes, et al. Sou homem e pai sim!(Re) construindo a identidade masculina a partir da participação no parto. Revista Panamericana de Salud Pública, v. 42, p. e190, 2019. Acesso em: 09 jan. 2020. Disponível em: https:/ / www.scielosp.org/article/rpsp/2018.v42/e190/pt/

CABRAL, Stella Mari de Souza Colhado; PEREZ, Deborah Karolina. Violência obstétrica: produção científica de psicólogos sobre o tema. ECOS-Estudos 
Contemporâneos da Subjetividade, v. 9, n. 2, p. 270-283, 2020. Acesso em: 04 fev. 2020. Disponível em: http:/ / www.periodicoshumanas.uff.br/ecos/article/view /2872

CAVALCANTI, Thais Rafaela Lira; HOLANDA, Viviane Rolim. Participação paterna no ciclo gravídico-puerperal e seus efeitos sob a saúde da mulher. Enfermagem em Foco, v. 10, n. 1, 2019. Acesso em: 20 jan. 2020. Disponível em: http:/ / revista.cofen. gov.br/index.php/enfermagem/article/view/1446

FRANCISCO, Bruna de Souza, et al. Percepções dos pais sobre suas vivências como acompanhantes durante o parto e nascimento. REME rev. min. enferm, p. 567-583, 2015. Acesso em: 23 jan. 2020. Disponível em: https:/ / pesquisa.bvsalud.org/gim/ resource/en/bde-28178?lang=en

GULLO, Caio Eduardo, et al. Cesárea eletiva no Brasil: imposição da autonomia da mulher ou do poder médico?. Enfermagem Brasil, v. 10, n. 6, p. 362-370, 2020. Acesso em: 04 fev. 2020. Disponível em: http:/ / portalatlanticaeditora.com.br/index.php/ enfermagembrasil/article/view/3887

HOLANDA, Sâmia Monteiro, et al. Influência da participação do companheiro no pré-natal: satisfação de primíparas quanto ao apoio no parto. Texto \& ContextoEnfermagem, v. 27, n. 2, 2018. Acesso em: 07 jan. 2020. Disponível em: http:/ /www. scielo.br/scielo.php?pid=S0104-07072018000200317\&script=sci_arttext\&tlng=pt

LOPES, Renata Silva, et al. O período gestacional e transtornos mentais: evidências epidemiológicas. Humanidades e tecnologia (FINOM), v. 1, n. 19, p. 35-54, 2020. Acesso em: 04 fev. 2020. Disponível em: http:/ / revistas.icesp.br/index.php/FINOM_ Humanidade_Tecnologia/article/view/932

MATOS, Mariana Gouvêa, et al. Construindo o vínculo pai-bebê: a experiência dos pais. Psico-USF, v. 22, n. 2, p. 261-271, 2017. Acesso em: 17 jan. 2020. Disponível em: http:/ / www.scielo.br/scielo.php?pid=S1413-82712017000200261\&script=sci_arttext

MELO, Raimunda Maria de, et al. Conhecimento de homens sobre o trabalho de parto e nascimento. Escola Anna Nery, v. 19, n. 3, p. 454-459, 2015. Acesso em: 23 jan. 2020. Disponível em: http:/ / www.scielo.br/scielo.php?pid=S1414$81452015000300454 \&$ script=sci_arttext\&tlng=pt

MENDES, Karina Dal Sasso; SILVEIRA, Renata Cristina de Campos Pereira; GALVÃO, Cristina Maria. Revisão integrativa: método de pesquisa para a incorporação de evidências na saúde e na enfermagem. Texto \& ContextoEnfermagem, v. 17, n. 4, p. 758-764, 2008. Acesso em: 27 jan. 2020. Disponível em: http:/ / www.scielo.br/scielo.php?pid=S0104-07072008000400018\&script=sci_arttext

MENDES, Rogério Cruz, et al. Man's perception of paternity during the postpartum gestation period. Research, Society and Development, v. 9, n. 1, p. 136911805, 2020. Acesso em: 05 fev. 2020. Disponível em: https:/ /rsd.unifei.edu.br/index.php/rsd/ article/view/1805 
NASCIMENTO, Adriana Oliveira, et al. A Importância do Acompanhamento Paterno no Pós-Parto e o Exercício da Paternidade. Revista de Pesquisa: Cuidado é Fundamental, p. 475-480, 2019. Acesso em: 14 jan. 2020. Disponível em: http:/ / ciberindex.com/index.php/ps/article/view/P112030

QUITETE, Jane Baptista; MONTEIRO, Jéssika Andrade de Melo Braga. A participação do pai no parto domiciliar planejado: um ato significativo para a mulher. Revista Enfermagem UERJ, v. 26, p. 18682, 2018. Acesso em: 23 jan. 2020. Disponível em: https://www.e-publicacoes.uerj.br/index.php/enfermagemuerj/article/view/18682

RIBEIRO, José Francisco, et al. Percepção do pai sobre a sua presença durante o processo parturitivo. Rev. enferm. UFPE on line, p. 1586-1592, 2018. Acesso em: 09 jan. 2020. Disponível em: file:/ / /C:/Users/Luis\%20Felipe/Downloads/234522114302-1-PB.pdf

SANTANA, Lucas Augusto; SILVA GONÇALVES, Bárbara Donnária. A participação do parceiro na rotina pré-natal da mulher gestante: estudo em uma Unidade Básica de Saúde. Humanidades e tecnologia (FINOM), v. 1, n. 20, p. 312-327, 2020. Acesso em: 04 fev. 2020. Disponível em: http:/ / revistas.icesp.br/index.php/FINOM_ Humanidade_Tecnologia/article/view/1007

SANTOS, Alisson Junior. Sintomas de depressão e ansiedade em mulheres no período pós-parto. Revista Atenas Higeia, v. 2, n. 1, p. 29-35, 2020. Acesso em: 04 fev. 2020. Disponível em: http:/ / www.atenas.edu.br/revista/index.php/higeia/article/ view/34

SERRÃO, Jeane Rodrigues Miranda, et al. Práticas de gestantes soropositivas para HIV sobre o autocuidado: Construção de Tecnologia Educacional em Saúde. Revista Eletrônica Acervo Saúde, v. 38, p. e1562-e1562, 2020. Acesso em 05 fev. 2020. Disponível em: https:/ / www.acervomais.com.br/index.php/saude/article/ view/1562

SILVA CARVALHO, Isaiane, et al. A participação do homem durante o nascimento do filho: vídeos do Youtube. Revista Enfermagem UERJ, v. 25, p. 11474, 2017. Acesso em: 20 jan. 2020. Disponível em: https:/ / www.e-publicacoes.uerj.br/index.php/ enfermagemuerj/article/view/11474

SILVA SANTOS, Rosângela; GONCALVES CAIRES, Tharine Louise. Sentimentos, sensações e emoções dos pais que vivenciaram o nascimento de seus filhos. Cienc. enferm, v. 22, n. 1, p. 125-133, 2016.

SILVA, Elza Monteiro, et al. Participação do companheiro nos cuidados do binômio mãe e filho: percepção de puérperas. Revista de Pesquisa, Cuidado é Fundamental Online, v. 8, n. 1, p. 3991, 2016. Acesso em: 17 jan. 2020. Disponível em: https:/ / search.proquest.com/openview/1a655bf403be11bc647ea5f45cde39cb/1?pqorigsite $=$ gscholar $\& \mathrm{cbl}=2030183$ 
SOUSA, Iury Gabriela Terreço. Queixas relacionadas à sexualidade no puerpério: uma revisão da literatura. Monografia, 2020. Acesso em: 05 fev. 2020. Disponível em: http:/ / repositorio.uft.edu.br/handle/11612/1624

SOUZA, Dhessica Victoria Rodrigues, et al. Construção de uma tecnologia educacional sobre depressão no período gravídico e puerperal: um relato de experiência. Revista Eletrônica Acervo Saúde, v. 39, p. e2365-e2365, 2020. Acesso em: 05 fev. 2020. Disponível em: https:/ / www.acervomais.com.br/index.php/saude/ article/view/2365 